\title{
Investigation on various welding consumables on properties of carbon steel material in gas metal arc welding under constant voltage mode
}

\author{
PRITESH PRAJAPATI* and VISHVESH J BADHEKA \\ Department of Mechanical Engineering, School of Technology, Pandit Deendayal Petroleum University, \\ Gandhinagar 382421, India \\ e-mail: pritesh.kitrc@gmail.com; vishvesh79@gmail.com
}

MS received 8 August 2016; revised 1 March 2017; accepted 7 March 2017; published online 28 August 2017

\begin{abstract}
In this present work, the influence of different consumables on weld properties of carbon steel plate was studied by automatic gas metal arc welding under constant voltage mode. For all experiments, the process parameters such as welding current of $200 \mathrm{~A}$, voltage of $28 \mathrm{~V}$ and welding speed of $200 \mathrm{~mm} / \mathrm{min}$ were kept constant. The results indicate that the angular distortion remained higher for solid wire, whereas it was minimum for flux-cored wire and the lowest in metal-cored wire. Mechanical properties such as yield strength, tensile strength, elongation and joint efficiency remained high for solid wire relative to cored wire. Excellent impact toughness of the weld metal and heat-affected zone was reported for the flux-cored welds compared with solid wire and metal-cored welds.
\end{abstract}

Keywords. GMAW; FCAW; MCAW; mechanical and metallurgical testing.

\section{Introduction}

The variants of gas metal arc welding (GMAW) use a tubular electrode, wherein metallic powder or flux powder is filled inside the tubular electrode, which is known as metal-cored arc welding (MVAW) and flux-cored arc welding (FCAW), respectively. Such electrodes require a gas shield to protect the molten weld pool from atmospheric contamination [1]. Tubular wires whose core consisted only of metallic ingredients, with no minerals, were used for hard facing earlier in the history of the process. However, in case of joining by metal-cored wire, it was felt that a slag was needed to improve weldability. The joining through metal-cored wire was well documented in British Patent 858854, March 29, 1957 [2]. Tubular wire was developed to obtain advantages of two existing processes. Manual metal arc electrodes contain a coating of flux, which protects from atmospheric contamination, forms a slag at weld surface, refines and supports the pool and contributes ionic species to stabilize and modify the arc. GMAW was introduced in the 1920s to allow continuous welding with its inherently greater productivity, but was limited, especially in positional welding, by its lack of slag formation capability. Hence, tubular wire of flux-cored wire was developed to solve this problem. Additionally, tubular wire provides a number of advantages such as excellent usability, productivity and metallurgical flexibility [3].

*For correspondence
In the 1950 s, metal-cored wires were introduced containing no fluxing agents, but only metal powders inside the tubular wires. The worldwide trends towards welding with metal-cored wires were undoubtedly driven by economics. A metal-cored wire carries both the advantages of solid wires and flux-cored wires. It was one of the fastest growing consumable and affords the biggest gain in the welding industry in terms of cost reduction through increased productivity and higher electrode efficiency [4]. The outer metallic shield of a flux-cored wire conducts most of the electrical current. Therefore, this large current-carrying capacity of outer metallic shield results in more $I^{2} R$ heating, and higher wire burn-off rate, which subsequently leads to higher productivity [5]. The current density is greater in case of tubular wires because of the tubular construction, which improves its deposition rates at equal current levels when compared with solid GMAW wires. Metal-cored wires, with their arc characteristics similar to those of solid GMAW wires, have low spatter formation as well as low slag volume, which also exhibit deposition efficiencies in the $92-98 \%$ range with the selection of spray transfer mode and shielding gas mixtures with high argon percentage. The internal components of a metal-cored wire are generally composed of alloying elements such as manganese, silicon and, in some cases, nickel, chromium and molybdenum as well as very small amounts of arc stabilizers such as sodium and potassium, with the balance being iron powder, in case of welding for steel-based workpiece. Deposition rates can be further increased by reducing the tube wall thickness, wherein 
metal powder filled with higher percentage acts as a large conductive area [6]. Flux-cored and metal-cored wires are capable of having deposition rates as high as $12-14 \mathrm{lb} / \mathrm{h}$ $(5.4-6.4 \mathrm{~kg} / \mathrm{h})$ for a 0.045 -in $(1.2-\mathrm{mm})$ diameter wire, compared with $8-10 \mathrm{lb} / \mathrm{h}(3.6-4.5 \mathrm{~kg} / \mathrm{h})$ for a solid wire of the same diameter. Higher deposition rates coupled with high deposition efficiencies and low slag volume allow the metal-cored wire to be used at higher travel speeds, resulting in increased productivity [7-9]. Travel speeds can often be raised by $30 \%$ or more by the use of metalcored wire, a significant benefit in a capital-intensive application [6]. Metal-cored tubular wires even in their standard form may be used for submerged arc welding given a suitable flux and equipment [10]. The slag formation in case of flux-cored wire enables the use of this process in all positions. On the contrary, the metal-cored arc wire has little non-metallic components in the core, which are limited to a maximum of $5 \%$ by weight. Thus, an MCAW bead cannot be deposited easily out of position and will not have a slag cover on the solidified weld. An MCAW surface will resemble that of a GMAW deposit, containing islands of metal silicates. Therefore, a multipass of MCAW requires minimal inter-pass cleaning. By contrast, a multi-pass of FCAW needs de-slagging between the weld passes in order to produce a quality weld [11].

Apart from these basic studies, the focused literatures on GMAW for different filler wires provide studies on operational performances and bead characteristics (such as geometry and microstructure) as well as mechanical and metallurgical properties of welding with different shielding gas mixtures of weld metal [7, 10, 12-17]. Furthermore, Prajapati et al [18] investigated GMAW for hybrid filler wires and reported interesting results. Nevertheless, hitherto, the GMAW process has been limitedly reported for weld properties comparisons with different filler wires of solid and tubular wires, to the best of authors' knowledge. Therefore, the influence of various welding consumables of GMAW on weld properties of carbon steel material is worth investigating. In the present investigation, the properties comparisons and performance analysis of welds obtained with different filler wires of GMAW are carried out, keeping all other process parameters constant.

\section{Base materials and filler wires}

A carbon steel plate of SA516Gr70 material was used as the base material. Welding consumables such as solid (ER70S6), flux-cored wire (E71T-1C) and metal-cored wire (E70C$6 \mathrm{M})$ with a nominal diameter of $1.2 \mathrm{~mm}$ were used, keeping all other process parameters constant. Chemical compositions of these wires and the base material are given in table 1. Welding coupons were prepared for the flat position on base metal SA516Gr70 of carbon steel plate,
Table 1. Chemical composition of the filler wire and SA516 Gr70 carbon steel material.

\begin{tabular}{lcccc}
\hline & $\begin{array}{c}\text { Solid } \\
\text { wire } \\
\text { (ER70S- } \\
\text { Contents }\end{array}$ & $\begin{array}{c}\text { Flux-cored } \\
\text { wire } \\
\text { (E71T-1C) }\end{array}$ & $\begin{array}{c}\text { Metal-cored } \\
\text { wire (E70C- } \\
6 \mathrm{M})\end{array}$ & $\begin{array}{c}\text { Base metal } \\
\text { (SA516Gr70) }\end{array}$ \\
\hline $\mathrm{C}$ & 0.07 & 0.03 & 0.048 & 0.186 \\
$\mathrm{Si}$ & 0.86 & 0.56 & 0.582 & 0.322 \\
$\mathrm{Mn}$ & 1.44 & 1.29 & 1.375 & 1.112 \\
$\mathrm{P}$ & 0.014 & 0.011 & 0.014 & 0.014 \\
$\mathrm{~S}$ & 0.008 & 0.005 & 0.012 & 0.009 \\
$\mathrm{Cr}$ & 0.025 & 0.04 & 0.023 & 0.030 \\
$\mathrm{Ni}$ & 0.014 & 0.02 & 0.014 & 0.026 \\
$\mathrm{Mo}$ & 0.002 & 0.01 & 0.001 & 0.019 \\
$\mathrm{~V}$ & 0.002 & 0.02 & 0.004 & 0.001 \\
$\mathrm{Nb}$ & N/A & N/A & 0.002 & Nil \\
$\mathrm{Cu}$ & 0.15 & 0.01 & 0.015 & 0.033 \\
\hline
\end{tabular}

Table 2. Mechanical properties of consumables.

\begin{tabular}{|c|c|c|c|c|}
\hline $\begin{array}{l}\text { Mechanical } \\
\text { properties }\end{array}$ & $\begin{array}{l}\text { Solid } \\
\text { wire }\end{array}$ & $\begin{array}{l}\text { Flux-cored } \\
\text { wire }\end{array}$ & $\begin{array}{l}\text { Metal- } \\
\text { cored wire }\end{array}$ & $\begin{array}{l}\text { Base } \\
\text { metal }\end{array}$ \\
\hline $\begin{array}{l}\text { Yield strength } \\
\quad(\mathrm{MPa})\end{array}$ & 427 & 605 & 448 & 446.9 \\
\hline $\begin{array}{l}\text { Tensile strength } \\
(\mathrm{MPa})\end{array}$ & 529 & 579 & 549 & 590.60 \\
\hline Elongation (\%) & 26 & 31 & 31 & 24.8 \\
\hline $\begin{array}{l}\text { CVN impact value, } \\
\left.\mathrm{J} \text { (temp., }{ }^{\circ} \mathrm{C}\right)\end{array}$ & $\begin{array}{l}35 \\
(30)\end{array}$ & $\begin{array}{c}80(-20) \\
103 \\
(-30)\end{array}$ & $\begin{array}{c}48(-29) \\
62 \\
(-18)\end{array}$ & $\begin{array}{l}20 \\
(30)\end{array}$ \\
\hline Shielding gas & - & $100 \% \mathrm{CO}_{2}$ & $\begin{array}{c}75 \% \mathrm{Ar}- \\
25 \% \\
\mathrm{CO}_{2}\end{array}$ & - \\
\hline
\end{tabular}

$300 \times 100 \times 10 \mathrm{~mm}$ in size, with a single $\mathrm{V}$-groove $\left(60^{\circ}\right)$. The mechanical properties of the different filler wires and base materials are given in table 2 .

\section{Experimental procedure}

Initially, the experiments of bead on plate were carried out on a SA516Gr70 carbon steel plate of dimensions $300 \times 100 \times 10 \mathrm{~mm}$, in order to set process parameters and welding conditions. Effects of different filler wires on the surface appearance of the weld bead and weld bead dimensions were studied, keeping all other welding variables constant. In the second stage, keeping welding variables constant, 10-mm-thick SA516Gr70 plates were welded with different filler wires like solid, flux cored and metal cored. The process parameters such as welding current of $200 \mathrm{~A}$, voltage of $28 \mathrm{~V}$, welding speed of $200 \mathrm{~mm} /$ min, the contact tip (the CTWD) at $15 \mathrm{~mm}$, shielding gas composition $90 \% \mathrm{Ar}+10 \% \mathrm{CO}_{2}$, shielding gas flow rate of 

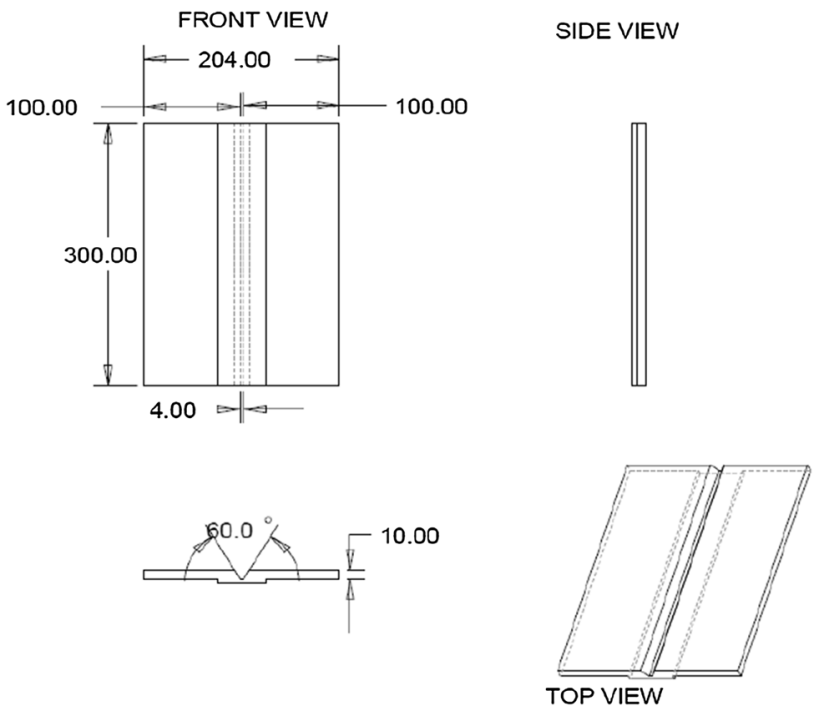

Figure 1. Shape and dimensions of "V" groove.

$25 \mathrm{l} / \mathrm{min}$ and electrode extension $8-10 \mathrm{~mm}$ were kept constant for all the experiments. Welding position of $1 \mathrm{G}$ was selected, and there were two passes applied to weld a 10-mm-thick plate of SA516Gr70. Joint design was kept fixed for all the experiments as per figure 1 .

The samples were subjected to measurement of angular distortion, just after the welding. Angular distortion measurement was carried out at three different locations of the coupon, such as at the start, middle and end of the plate. An average of three readings is presented here. Next to this, the welded joints were subjected to non-destructive test (such as radiography test) and destructive test (of mechanical testing that includes analysis of yield strength, tensile strength, \% elongation, bend test and impact test). These different testings and analyses were carried out as per ASME section IX [19]. The Charpy impact test was conducted for a specimen with a V-notch that was prepared perpendicular to the weld axis. This was tested out at a cryogenic temperature of $-49^{\circ} \mathrm{C}$. Further, the traverse specimens were cross sectioned from the welded plates for macro-structure observation. These specimens were subjected to grinding and polishing on a bench grinder with grit papers of 120 and 320 grades. Then these specimens were etched with $8 \%$ Nital solution (of $96 \% \mathrm{HNO}_{3}$ and $4 \%$ methanol) for 2-3 min. To verify the structural homogeneity, the macro- and micro-Vickers hardness tests were carried at $10 \mathrm{~kg}$ and $300 \mathrm{~g}$, respectively. The measurements were carried out in the transverse as well as longitudinal direction for each indentation at $1 \mathrm{~mm}$.

\section{Results and discussion}

\subsection{Comparative evaluation of the welding current, voltage and heat input}

In accordance with table 3 , it is confirmed that the current values recorded by the data monitoring system were found to be the highest in solid wire compared with metal-cored wire. Tubular wire (wall thickness) can have less electrical resistance per unit length than a solid wire of the same diameter because the tubular wire is made of a very soft steel. Besides, the solid wire contains more than $1 \%$ manganese and almost as much silicon and so it works at a faster rate as its electrical resistivity is higher, which leads to higher heat input [20]. Additionally, cored wires often run at lower voltage than solid wires because of lesser electrical resistance of the cored wire per unit length than that of solid wires of the same diameter.

Values of manganese and silicon for the solid wire were higher compared with tubular wires (see table 1). Because of these higher manganese and silicon values in solid wire, higher electrical resistance was expected compared with tubular wires, which subsequently increased the heat input during GMAW of solid wire.

\subsection{Angular distortion and peak temperature}

Angular distortion measurement was carried as per the procedure shown in figure 2 . The dial indicator was moved by distance of $\Delta X$ along the $x$-axis, and then a vertical displacement $\Delta Z$ was obtained. Finally, the angular distortion value $\theta$ was calculated from the following equation [21]:

$$
\theta=\tan ^{-1} \frac{\Delta Z}{\Delta X}
$$

Average angular distortion values are presented in table 4. In the present context, comparison among solid, flux-cored and metal-cored wire shows that the angular distortion is the lowest with metal-cored wire, whereas it is higher for the other cases, especially with solid wire.

Table 3. Welding variables (set and actual values).

\begin{tabular}{|c|c|c|c|c|c|c|c|c|}
\hline \multirow[b]{2}{*}{ Welding process } & \multicolumn{2}{|c|}{$I(\mathrm{~A})$} & \multicolumn{2}{|c|}{$V(\mathrm{~V})$} & \multirow{2}{*}{$\begin{array}{l}\text { Welding speed }(\mathrm{mm} / \mathrm{min}) \\
\text { Set }\end{array}$} & \multicolumn{2}{|c|}{ Heat input $(\mathrm{kJ} / \mathrm{mm})$} & \multirow[b]{2}{*}{ No. of passes } \\
\hline & Set & Avg. (*) & Set & Avg. (*) & & Calculated & Cal. avg. (*) & \\
\hline GMAW (solid wire) & 200 & 279.5 & 28 & 28.05 & 200 & 1.68 & 2.35 & 02 \\
\hline Flux cored arc welding & 200 & 277.5 & 28 & 27.95 & 200 & 1.68 & 2.32 & 02 \\
\hline Metal cored arc welding & 200 & 228.5 & 28 & 28 & 200 & 1.68 & 1.91 & 02 \\
\hline
\end{tabular}

Actual $(*)$ : values recorded by the online data monitoring system (during welding). 

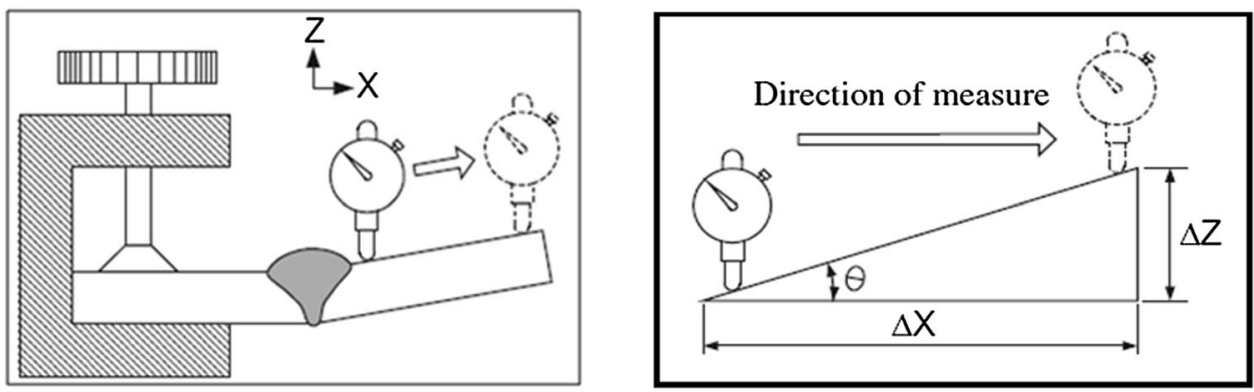

Figure 2. Angular distortion measurement.

Table 4. Angular distortion and peak temperature data.

\begin{tabular}{lcccc}
\hline $\begin{array}{l}\text { Welding } \\
\text { process }\end{array}$ & $\begin{array}{c}\text { Vertical } \\
\text { displacement } \\
\Delta Z(\mathrm{~mm})\end{array}$ & $\begin{array}{c}\text { Horizontal } \\
\text { displacement } \\
\Delta X(\mathrm{~mm})\end{array}$ & $\begin{array}{c}\theta \\
(\mathrm{deg})\end{array}$ & $\begin{array}{c}\text { Peak } \\
\text { temperature } \\
\left({ }^{\circ} \mathrm{C}\right)\end{array}$ \\
\hline $\begin{array}{l}\text { GMAW } \\
\text { (solid }\end{array}$ & 4.98 & 100 & 2.27 & 441 \\
$\quad$ wire $)$ & & & & \\
$\begin{array}{l}\text { Flux- } \\
\text { cored }\end{array}$ & 4.66 & 100 & 2.66 & 407 \\
arc \\
welding
\end{tabular}

During this investigation, the heat input of GMAW with solid wire was reported to be the maximum as compared with FCAW and MCAW, which may be the reason for the high distortion observed with solid wire (figure 3 ).

\subsection{Peak temperature}

During welding, the temperature measurements were carried out at the centre of the plate using a K-type contact thermocouple device. Table 4 shows the average peak temperature values for welds obtained with different consumables. Average peak temperature with solid wire is higher compared with tubular wire, which is because of high input recorded for the weld of solid wire (see table 3).

\subsection{Radiography testing}

Radiography test was carried out as per ASME section IX [22] for all the samples. Following conditions were used for radiography testing: radiation of IR-192, exposure of 1 , laser D-7, screen of lead, front of $0.10 \mathrm{~mm}$, back of $0.15 \mathrm{~mm}$, SWSI technique, processing of $5 \mathrm{~min}$ and temperature at $20{ }^{\circ} \mathrm{C}$ for the full size of film like 3 in $\times 15$ in (each sample).

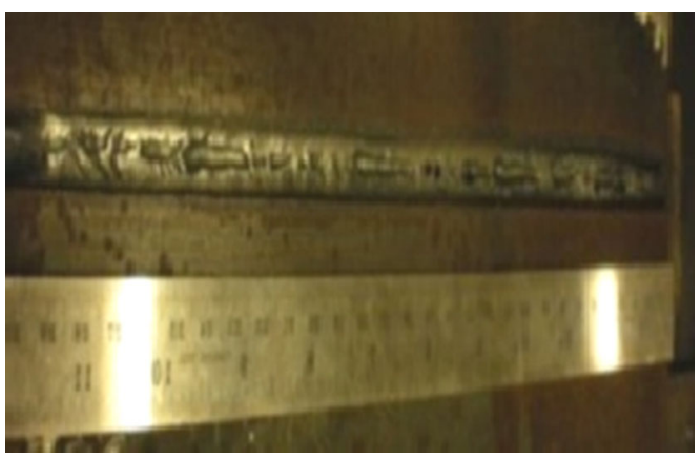

Figure 4. Photograph of chicken marks reported for weld of fluxcored arc welding.

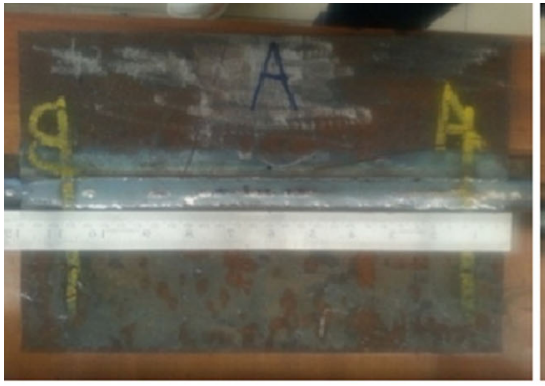

GMAW

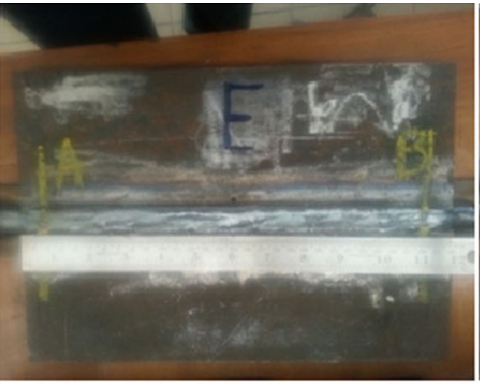

FCAW

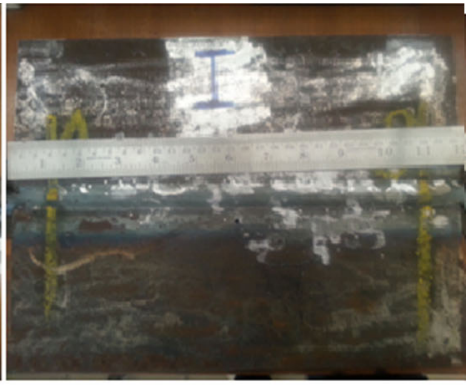

MCAW

Figure 3. Photographs of welded plates. 
Table 5. Macro-photographs with depth of penetration and HAZ width in mm.

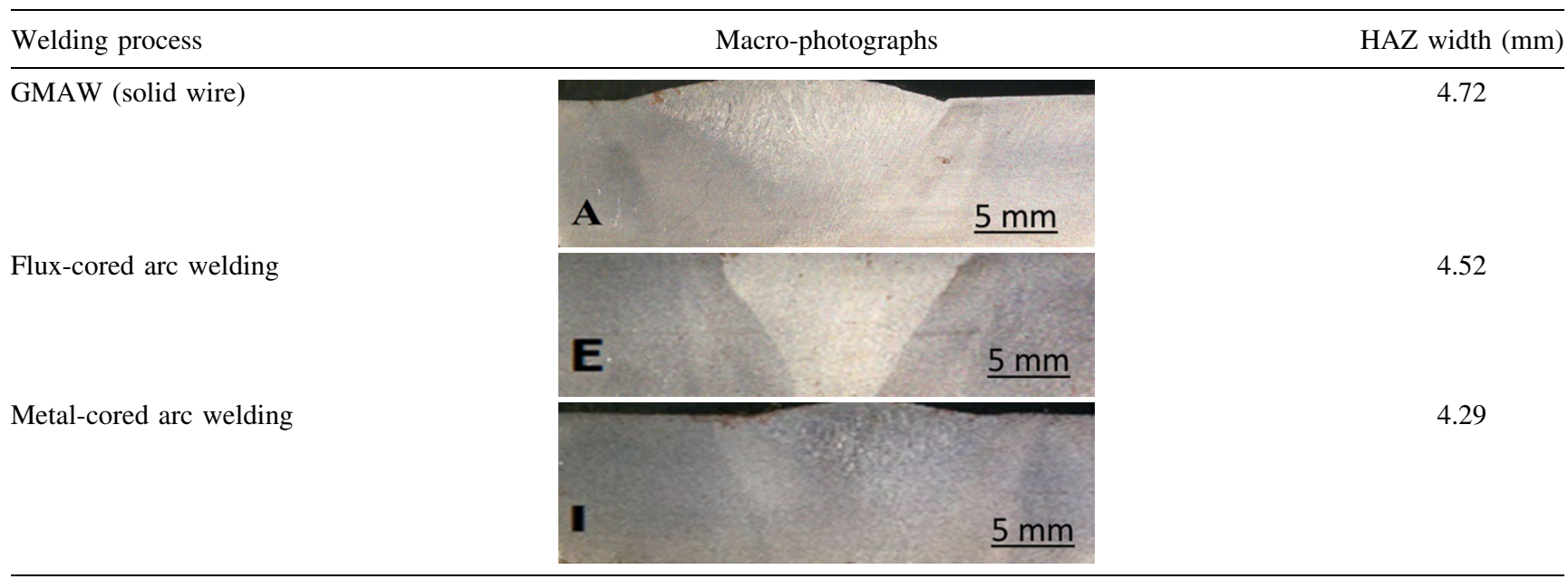

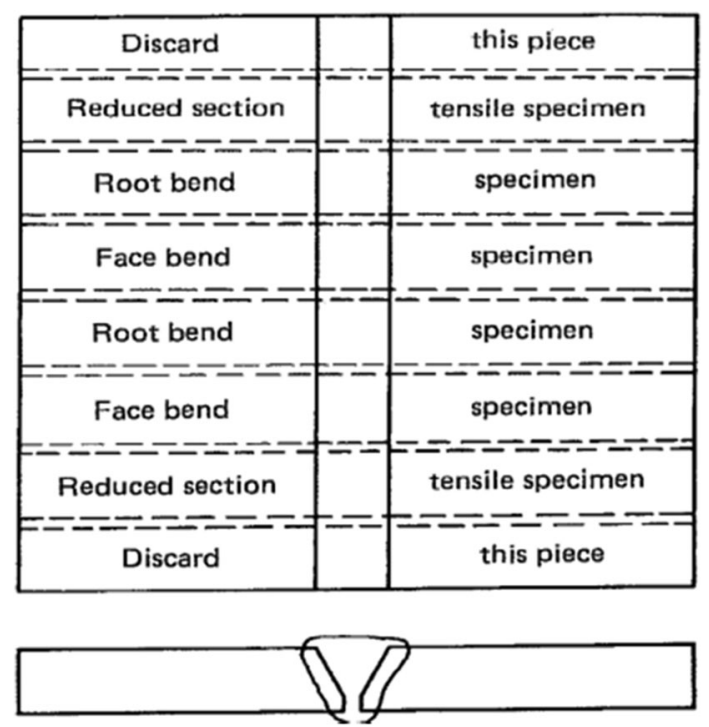

Figure 5. Plate less than $19 \mathrm{~mm}$ in thickness, procedure qualification [22].

All the samples cleared the radiography test, which shows the soundness of welded coupons. However, some marks were observed in case of weld obtained by FCAW. These marks were reported due to presence of chicken marks at the front surface of the weld as evidenced in figure 4. These chicken marks were reported because of slag formation, as the slag may lead to entrapment of gases into weld puddle, especially at the top surface. Similar results were reported by Prajapati et al [18] when flux-cored wire was applied at the top run.

\subsection{Macrostructure and heat-affected zone}

Macrostructure results are shown in table 5. It is clear from table 5 that higher depth of penetration (DOP) for solid wire compared with metal-cored and flux-cored wires is observed. This is because of higher electrical resistance of solid wire compared with cored wires. Higher electrical resistance of solid wire leads to higher width of heat-affected zone (HAZ) due to higher heat input.

The tubular wires were made up of a solid metallic sheath and filled with a powder. Hence, most of the current was carried by the solid metallic sheath. This consequently increases the diameter of the plasma arc, and leads to the low penetration or softer arc. Because of the axial metal transfer characteristics in spray transfer with solid wire, the penetration pattern was narrower and deeper than that of a tubular wire, as the power of two arcs are the same in this case. Therefore, the areas melted in the base metal were equal, but different in shape [23].

\subsection{Mechanical testing}

4.6a Tensile test: Standard test specimens were generated for the tensile testing with each condition as mentioned in figure 5. Specimens were prepared and tested as per standards of ASME section IX [22]. During testing, the tensile strength, yield strength and elongation $(\%)$ were recorded. The results of the same are presented in table 6. No major variations in the tensile properties were reported as the chemical compositions of filler wires were the same along with process parameters. However, minimum tensile strength was reported for FCAW, which may be due to the presence of minor defects such as chicken marks. Better tensile properties were reported for the welds made by solid wire of GMAW process. Figure 6 shows the fracture location of tensile specimens after testing. Results show that weld area of all the welds was noted to be sound as the fracture occurred from outside the weld zone.

4.6b Bend test: The bend test was conducted as per guidelines of ASME section IX, in order to check the soundness of the welds from front as well as rear sides. The bend test conditions are as follows: mandrill diameter of 


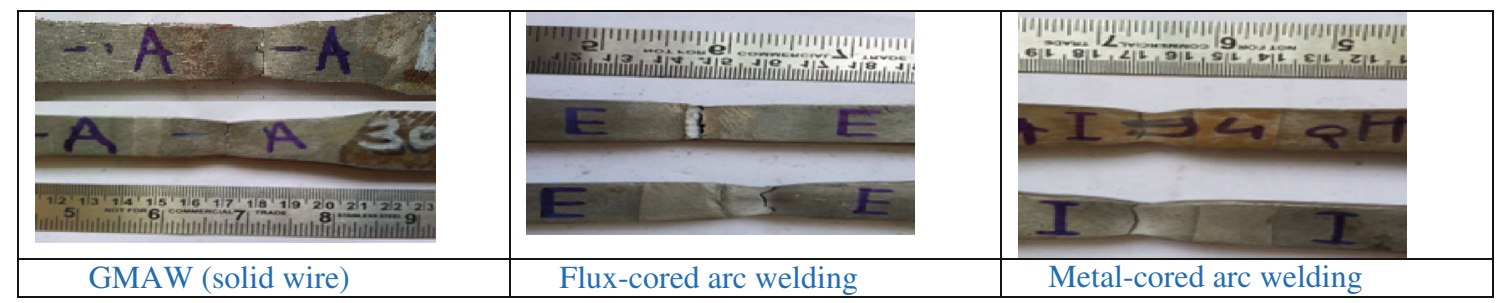

Figure 6. Fracture location of tensile test specimens.

Table 6. Yield strength, tensile strength and elongation (\%) for welded joints.

\begin{tabular}{lccc}
\hline Welding process & $\begin{array}{c}\text { Yield strength } \\
(\mathrm{MPa})\end{array}$ & $\begin{array}{c}\text { Tensile } \\
\text { strength }(\mathrm{MPa})\end{array}$ & $\begin{array}{c}\text { Elongation } \\
(\%)\end{array}$ \\
\hline $\begin{array}{l}\text { GMAW (solid } \\
\text { wire) }\end{array}$ & 384.75 & 583.85 & 26.20 \\
$\begin{array}{c}\text { Flux-cored arc } \\
\text { welding }\end{array}$ & 358.45 & 565.05 & 23.10 \\
$\begin{array}{c}\text { Metal-cored arc } \\
\text { welding }\end{array}$ & 381.00 & 535.95 & 20.00 \\
\hline
\end{tabular}

$38 \mathrm{~mm}$ and $180^{\circ}$ angle of bend were applied to perform the bend test. Results of bend test are shown in figure 7. It can be seen from figure 7 that all the welded joints have cleared the bend test from root as well as face sides. These bend test samples show good integrity of welded joints. It can be noted that the minor defect reported from radiography of FCAW has not affected the bend test as it was only a cosmic imperfection sort of defect. Similar results were reported by the same group of authors [18].

4.6c Impact toughness: Samples prepared from multi-pass welds were used for the Charpy test complying with the temperature conditions established by standard ASTM E23, 2002A [19]. For each condition, three specimens were prepared from weld as well as HAZ. The V-notch Charpy impact test was carried out at $-49^{\circ} \mathrm{C}$ temperature, wherein the specimen size was kept at $10 \mathrm{~mm} \times 7.50 \mathrm{~mm}$.

Table 7 shows the results of Charpy test for impact toughness in weld zone as well as HAZ. In case of

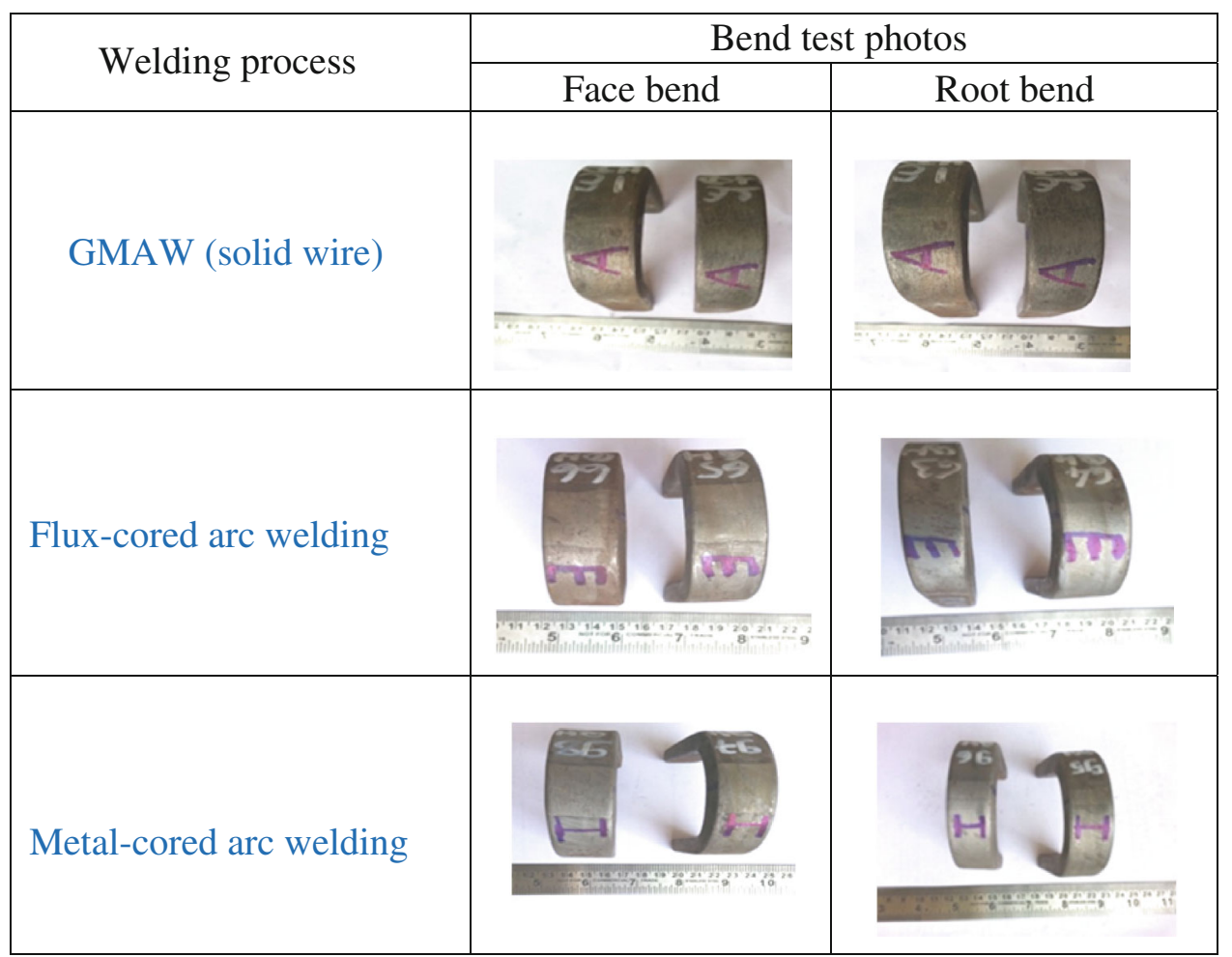

Figure 7. Bend test samples photographs. 
Table 7. Values of energy absorbed in the Charpy test for the welded samples.

Charpy impact test at $-49^{\circ} \mathrm{C}$. Energy absorbed $(\mathrm{J})$

\begin{tabular}{lll}
\cline { 2 - 3 } Welding process & Weld & HAZ \\
\hline GMAW (solid wire) & 18.67 & 16.67 \\
Flux-cored arc welding & 42.67 & 35.33 \\
Metal-cored arc welding & 18.00 & 21.33 \\
\hline
\end{tabular}

sample welded with flux-cored wire, the impact toughness was higher compared with solid and metal-cored samples. Higher impact property of weld and HAZ of flux-cored wire was reported because of shielding conditions, as flux-cored wire has two different shielding modes: one through the shielding gas and another through the self-flux shielding. These shielding conditions reduce the chances of oxidization of the weld metal and finally improve impact toughness. Also, the flux particles may have provided toughness property inside the weld before formation of slag. However, for heavy section thickness of workpiece, especially under multi-pass process, additional care is required for cleaning slag before applying subsequent second pass. Otherwise, it forms inclusions and reduces the impact value. Impact energy for weld and HAZ is shown in figure 8 .

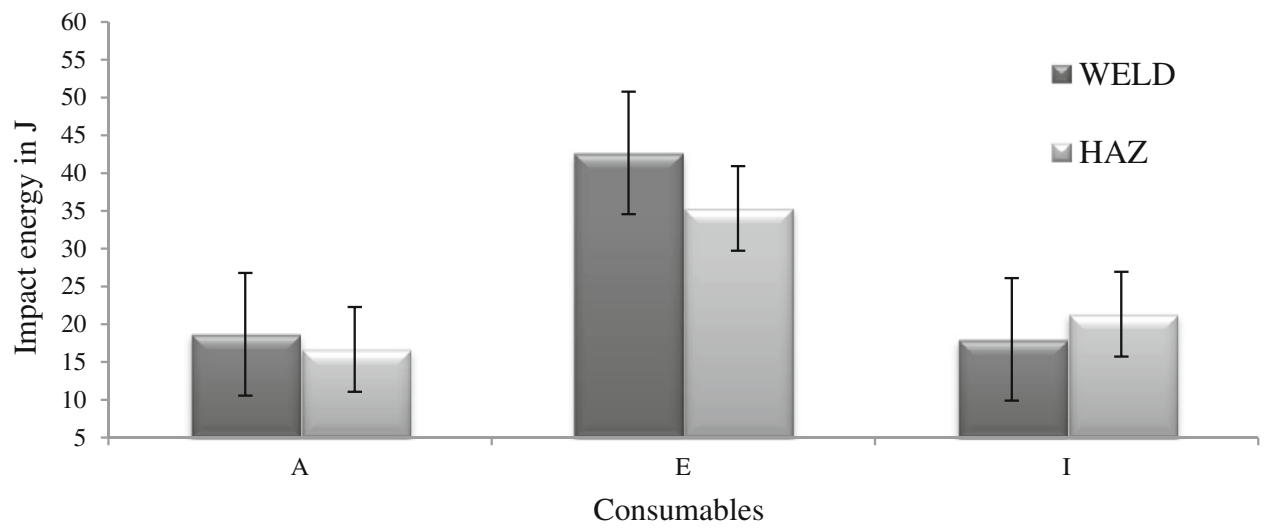

Figure 8. Impact energy for weld and HAZ

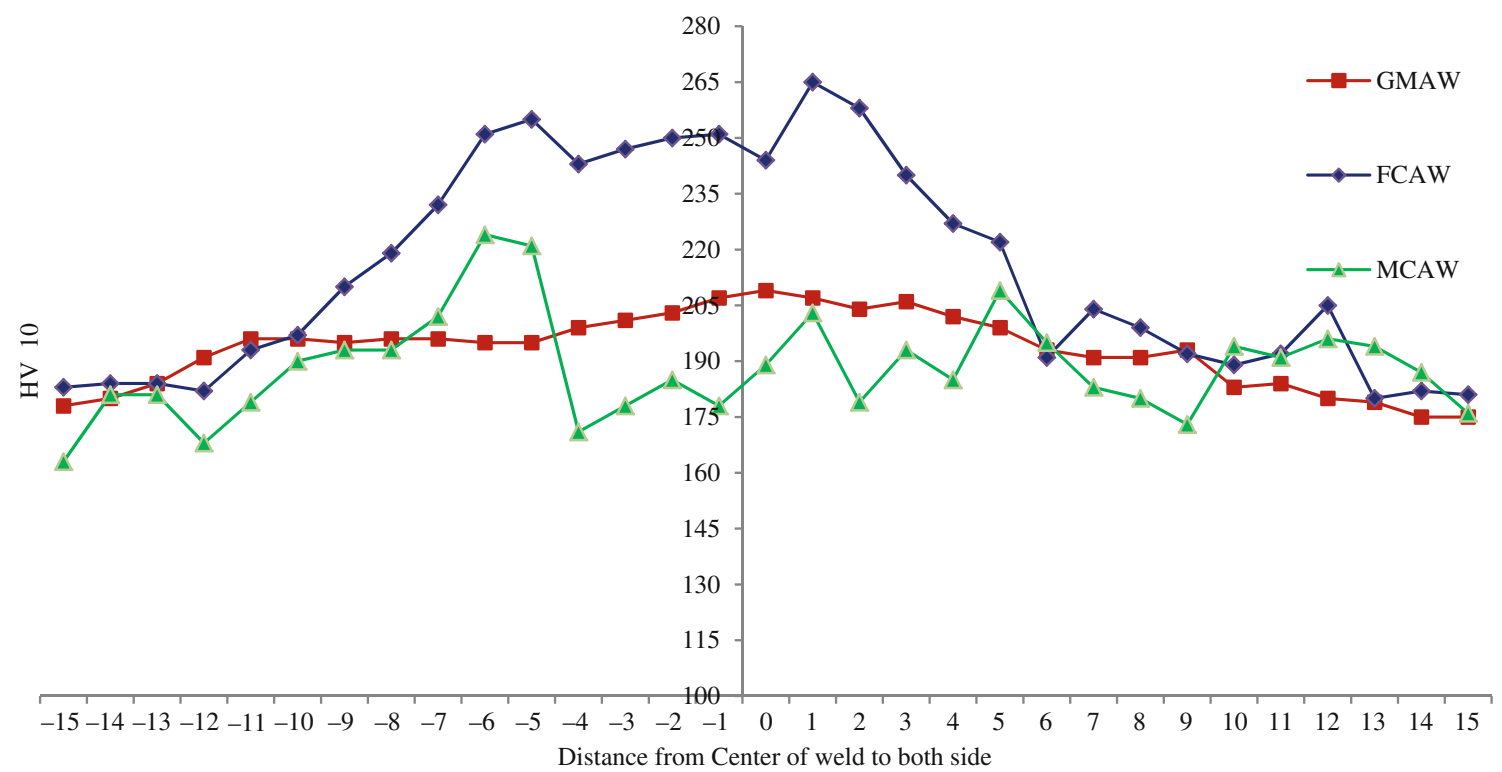

Figure 9. Average of VHN in different (transverse direction) zones at HV10. 


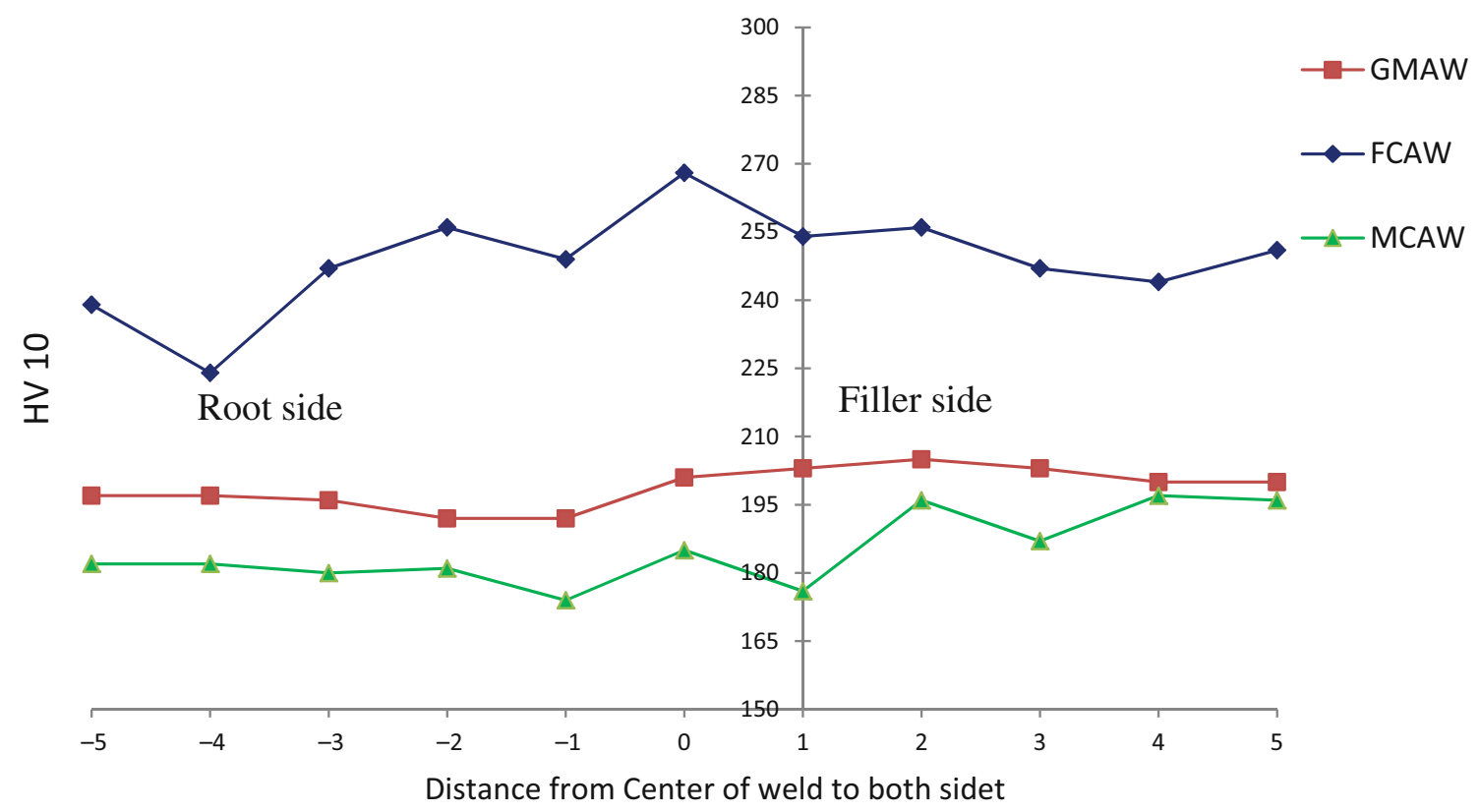

Figure 10. Average of VHN in different (vertical direction) zones at HV10.

\subsection{Macro- and micro-hardness evaluation}

Standard specimens were prepared for measurement of the Vickers Hardness Number (VHN). Vickers hardness was measured as per standard ASTM A 370-07 in both transverse direction of cross section (through weld metal, HAZ and parent metal) and vertical direction (through root to filler pass). The specimens prepared for macrostructure observations were utilized for VHN measurement. Each indentation was separated by $1 \mathrm{~mm}$ at a load of $10 \mathrm{~kg}$ for macro-hardness, whereas a load of $300 \mathrm{~g}$ was applied for micro-hardness. Figures 9-12 show the results of VHN under mentioned macro- and micro-loads for transverse and vertical directions. VHN number was higher for flux-cored wire as compared with other wires measurement in vertical (root to filler pass) direction as shown in figure 10. There were minor variations reported in VHN at the root to filler pass for GMAW and MCAW as shown in figure 11. Microhardness values were higher for FCAW compared with GMAW and MCAW samples as shown in figure 10. Micro-

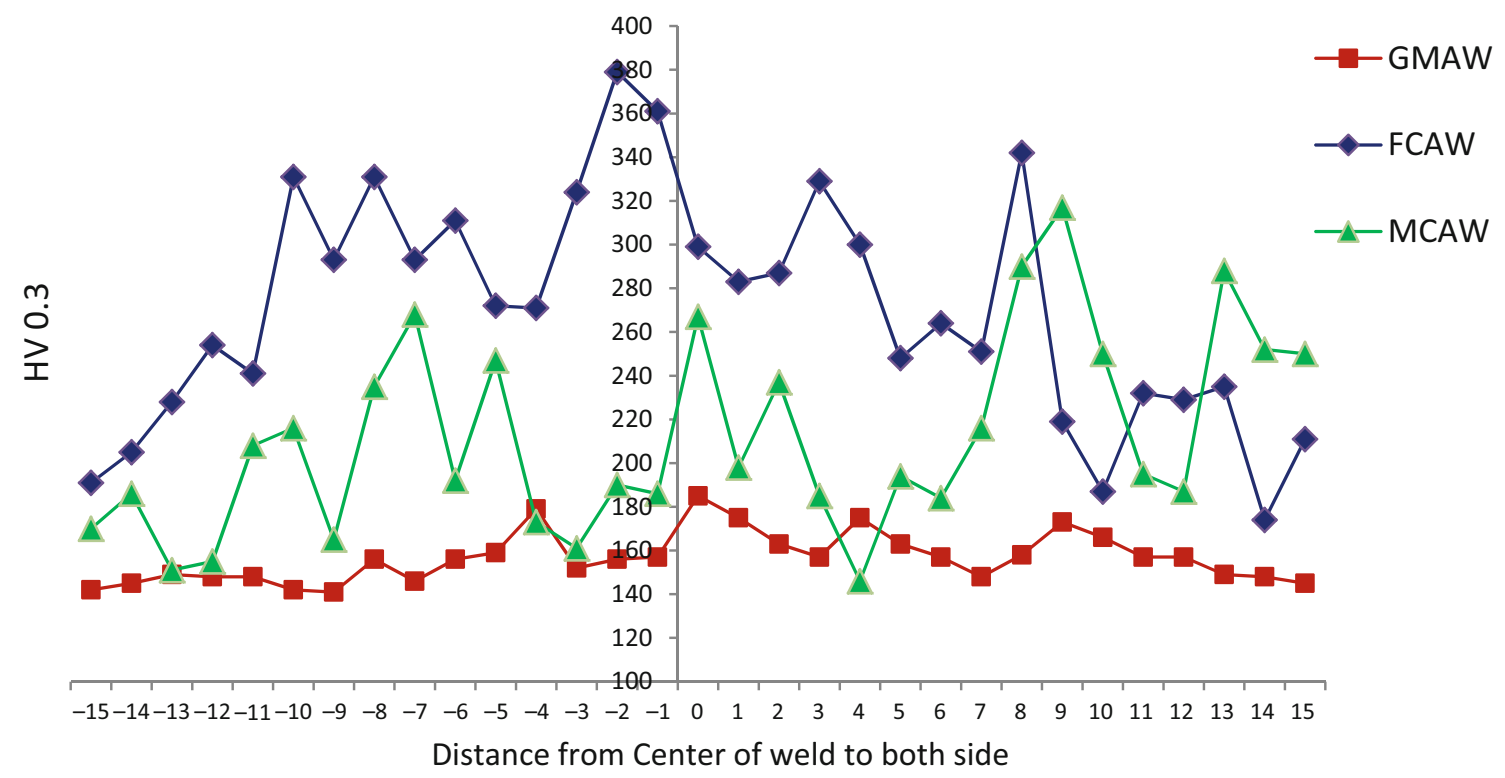

Figure 11. Average of VHN in different (longitudinal direction) zones at HV10. 


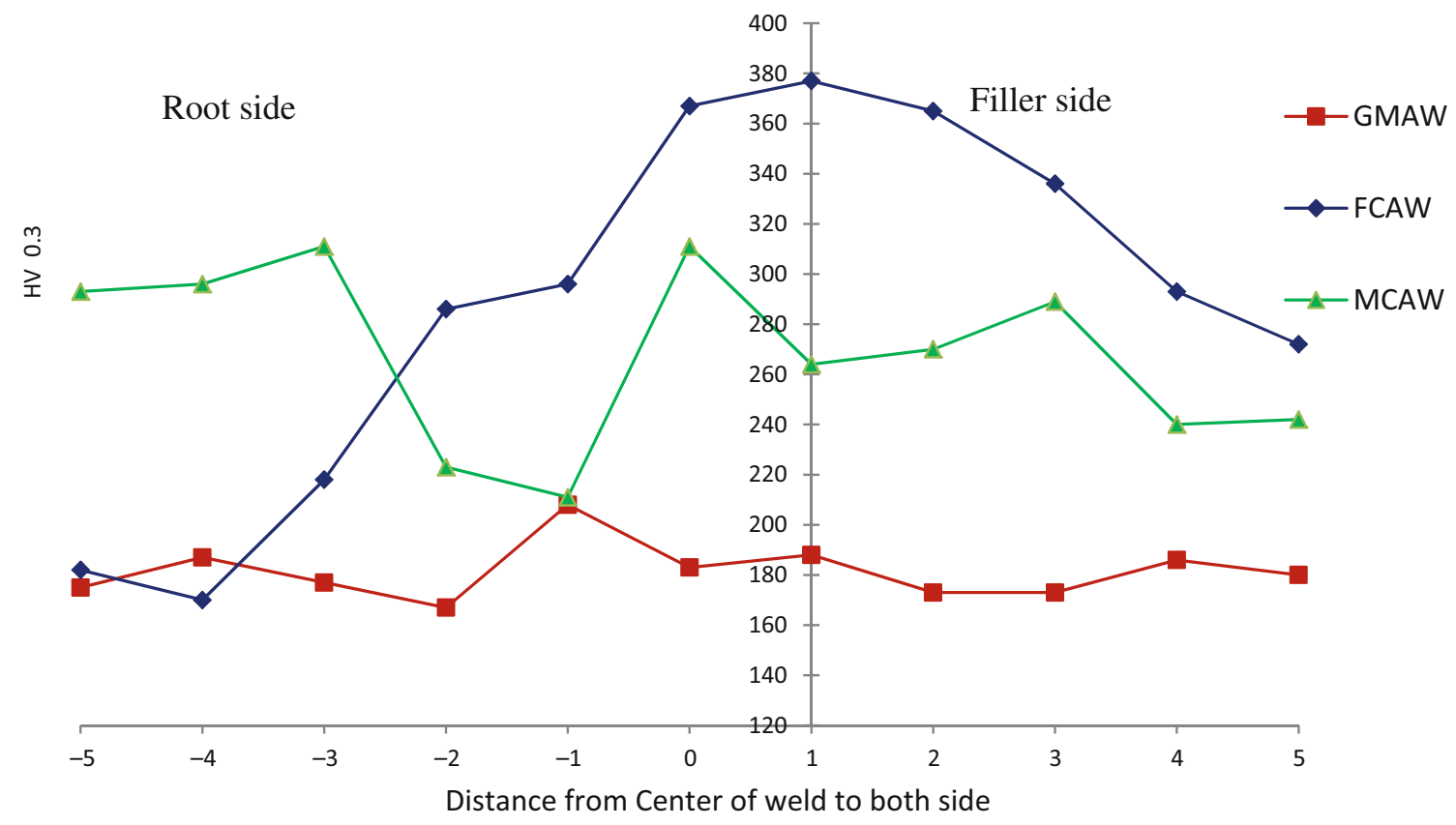

Figure 12. Average of VHN in different (transversal direction) zones at HV0.3.

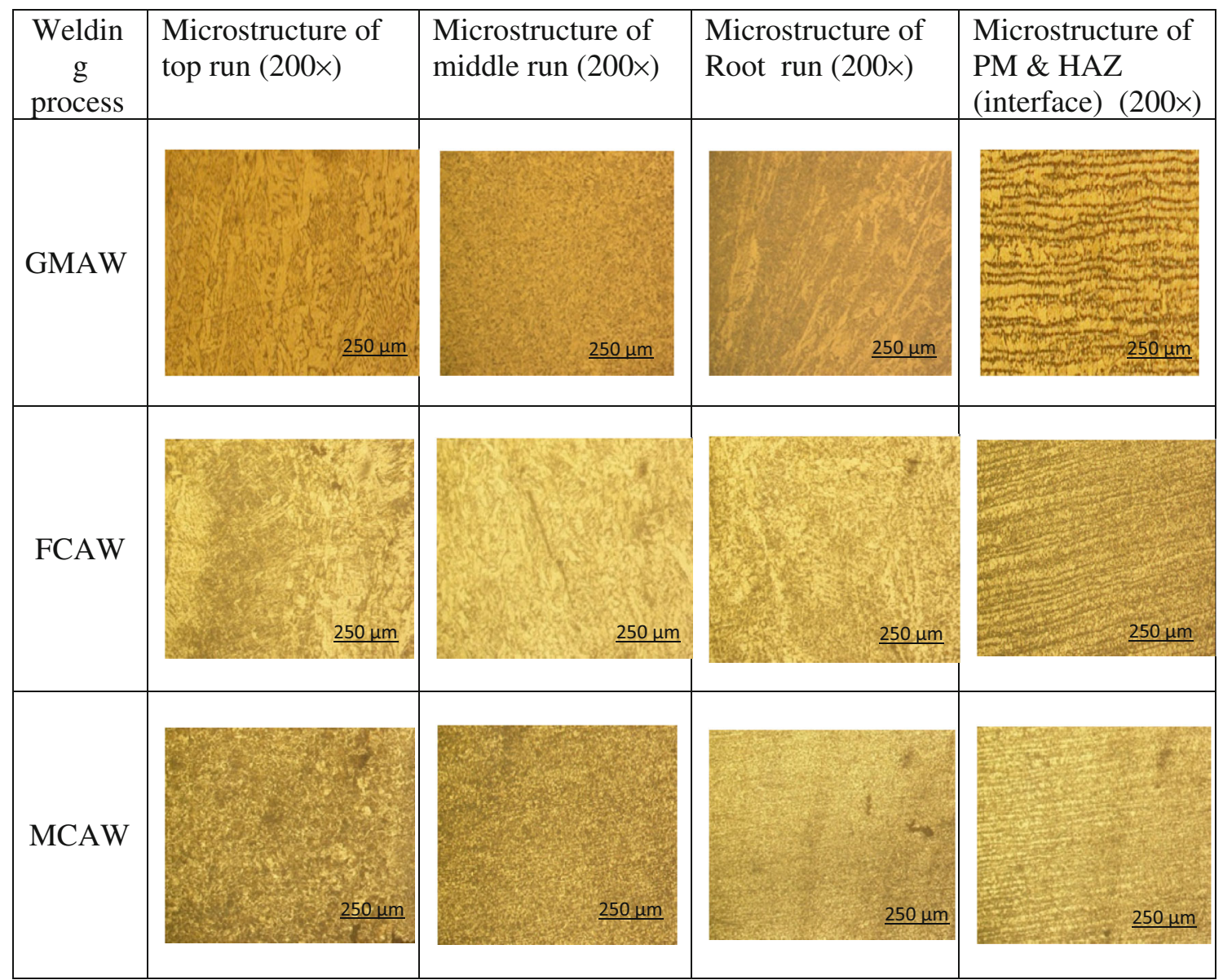

Figure 13. Summary of microstructure photos. 
hardness variation from root to filler was higher for FCAW relative to MCAW and GMAW as shown in figure 12. These variations reported may be due to different output performances, which was experienced because of different constructions of filler wires. Higher output current and higher heat inputs may be the main reasons for the higher hardness at respective zones [18].

\section{Weld metal microstructure}

All metallographic specimens were prepared by mechanical grinding and subsequent polishing (120, 320 grit silicon carbide, $1 / 0,2 / 0,3 / 0,4 / 0$ and 5/0) followed by etching through $8 \%$ Nital solution (such as $96 \% \mathrm{HNO}_{3}$ and $4 \%$ methanol) by swabbing it on the transverse side of the specimen. Microstructure examination was carried out using a light optical microscope. The specimens for metallographic examination were sectioned to the required size of the joint comprising weld metal, HAZ and base metal regions. Figure 13 shows the microstructure details of the weld, HAZ and parent metal under different conditions. Its major components include allotriomorphic ferrite, Widmanstätten ferrite and acicular ferrite. Microstructure investigation reflects extremely fine grain structure of weld and HAZ as well.

Typical microstructures reported in literatures [23] and [24] are in close association with microstructure reported in the present investigation. There were some of the martensitic structure, retained austenite and degenerated pearlite reported in the microstructural examination of all the samples. These latter phases occur in very small fractions, and are known by the collective term micro-phases. The microstructure depends primarily on the chemical compositions and cooling rate. In weld metal, in addition to chemical compositions and cooling rate, the presence of inclusion plays an important role in influencing microstructural changes as secondary consideration. The weld metal composition is a function of the composition of the shielding gas, welding wire, base metal and time allowed for reaction. The cooling rate is a direct function of heat input, plate thickness and the preheat temperature, and an indirect function of current, voltage, travel speed and heat transfer efficiency. Therefore, for a given welding wire, base plate, operating conditions, weld metal composition and cooling rate may have been influenced by the different construction of the filler wires, which consequently led to different microstructures at the same time.

\section{Conclusions}

- Angular distortion was maximum with solid wire and minimum for the weld of flux-cored wire and lowest in metal-cored wire.
- Average peak temperature was reported to be higher for weld of solid wire compared with the cored wire.

- During tensile test, all specimens failed from the parent materials, outside the weld zone. Hence, it can be stated that the welded joints are stronger than the parent metal.

- Samples welded with different consumables have showed good integrity of welded joints during the bend test.

- Excellent impact toughness of the weld metal and HAZ was reported for the flux-cored welds compared with solid and metal-cored welds.

- Higher macro- and micro-hardness values were reported for flux-cored welds relative to solid and metal-cored welds.

- Weld metal microstructure confirms the presence of allotriomorphic ferrite, Widmanstätten ferrite and acicular ferrite in the weld metal.

\section{Aknowledgements}

The authors want to express their aknowledgement to Dr. Kush P. Mehta for his significant supports at manuscript reviewing and executing revisions. The authors would like to thank Department of Science and Technology (DST), INDIA for the project of SR/FTP/ETA-19/08.

\section{References}

[1] AWS 2000 Welding handbook, vol 2, 8th ed., pp. 110-155

[2] Widgery D 1994 Tubular wire welding. India: Jaico Publishing House

[3] Barhost S 2000 Metal cored electrodes: basics. Weld. J. 79(11): 13-15

[4] Myers D 2002 Advantages and disadvantages. Weld. J. 81(9): 39-42

[5] Kevin L1996 Metal cored wires. Where do they fit in the future? Weld. J. 75(10): 35-38

[6] Vaidya V V 2002 Theory and practice of shielding gas mixtures for semi-automatic welds. Weld. J. 87: 43-48

[7] Mirza R M and Gee R 1999 Effects of shielding gases on weld-diffusible hydrogen contents using cored wires. Sci. Technol. Weld. Join. 4(2): 104-111

[8] Starling C M D, Modenesi P J and Borba T M D 2010 Comparison of operational performance and bead characteristics when welding with different tubular wires. Weld. Int. 24(8): 579-592

[9] Ramini de Rissone N M, Svoboda H G, Surian E S and de Vedia L A 2005. Influence of procedure variables on C-MnNi-Mo metal cored wire ferritic all-weld metal. Weld. J. 84(9): 139-s-148-s

[10] Suban M and Tusek J 2001 Dependence of melting rate in MIG/MAG welding on the type of shielding gas used. $J$. Mater. Process. Technol. 119: 185-192 
[11] Badheka V J 2013 Effect of metal-cored arc welding process parameters on weld bead geometry. Weld. Cutt. 12(2): 106-111

[12] ASME 2001 Pressure vessel and boiler code. New York (NY): ASME. Section VIII. Division 1 UG-84 and UCS-56, pp. $56-60$

[13] Mario Teske M and Fabio Martins F 2010 The influence of the shielding gas composition on GMA welding of ASTM A 516 steel. Weld. Int. 24(3): 222-230

[14] Bang K S, Jung D H, Park C and Chang W S 2008 Effect of welding parameters on tensile strength of weld metal in flux cored arc welding. Sci. Technol. Weld. Join. 13(6): 509-514

[15] Mukhopadhyay S and Pal T K 2006 Effect of shielding gas mixture on gas metal arc welding of HSLA steel using solid and flux-cored wires. Int. J. Adv. Manuf. Technol. 29(3-4): 262-268

[16] ASM 1993 Welding, brazing and soldering. In: American society of metals handbook, vol. 6, pp. 582-583

[17] Kannan T and Yoganandh J 2010 Effect of process parameters on clad bead geometry and its shape relationships of stainless steel claddings deposited by GMAW. Int. J. Adv. Manuf. Technol. 30: 1083-1095
[18] Prajapati P, Badheka V J and Mehta K P 2017 Hybridization of filler wire in multi-pass gas metal arc welding of SA516 Gr70 carbon steel. Mater. Manuf. Process. doi:10.1080/ 10426914.2016.1244847

[19] ASTM 1998 Metals test methods and analytical procedures. West Conshohocken, PA: ASTM, E-23, Section 3, pp. 138-157

[20] PRAXAIR Gas metals arc welding of carbon steel. http:// pdiimages.praxair.com/PDIB2CImages/pxd-pdf/praxair-starwelding-gases.pdf

[21] Murugan V V and Gunaraj V 2005 Effects of process parameters on angular distortion of gas metal arc welded structural steel plates. Weld. J. 11: 165-171

[22] ASME 2001 Pressure vessel and boiler code. New York, NY: ASME, Section IX, Division 1 UG-84 and UCS-56, pp. 111-112

[23] Myers T Choosing a shielding gas for FCAW. Cleveland, Ohio: The Lincoln Electric Co

[24] Bhadeshia H K D H and Honeycombe R 2006 Steels: microstructure and properties, 3rd ed., London: ButterworthHeinemann 